\title{
Preliminary clinical experience with a bifurcated Y-graft Fontan procedure-A feasibility study
}

\author{
Kirk R. Kanter, MD, ${ }^{\text {a }}$ Christopher M. Haggerty, BS, ${ }^{\mathrm{b}}$ Maria Restrepo, BS, ${ }^{\mathrm{b}}$ Diane A. de Zelicourt, PhD, \\ Jarek Rossignac, $\mathrm{PhD},{ }^{\mathrm{c}}$ W. James Parks, MD, ${ }^{\mathrm{d}}$ and Ajit P. Yoganathan, $\mathrm{PhD}^{\mathrm{b}}$
}

Objective: Optimizing flow and diminishing power loss in the Fontan circuit can improve hemodynamic efficiency, potentially improving the long-term outcomes. Computerized modeling has predicted improved energetics with a Y-graft Fontan.

\begin{abstract}
Methods: From August to December 2010, 6 consecutive children underwent completion Fontan $(\mathrm{n}=3)$ or Fon$\tan$ revision $(\mathrm{n}=3)$ using a bifurcated polytetrafluoroethylene Y-graft $(18 \times 9 \times 9 \mathrm{~mm}$ in 2, 20 $\times 10 \times 10 \mathrm{~mm}$ in 4) connecting the inferior vena cava to the right and left pulmonary arteries with separate graft limbs. The patents underwent magnetic resonance imaging $(n=5)$ or computed tomography $(n=1)$. Computational fluid dynamics assessed Fontan hemodynamics, power loss, and inferior vena cava flow splits to the branch pulmonary arteries. The clinical parameters were compared with those from 12 patients immediately preceding the present series who had undergone a lateral Fontan procedure.
\end{abstract}

Results: Despite longer crossclamp and bypass times (not statistically significant), the Y-graft Fontan patients had postoperative courses similar to those of the conventional Fontan patients. Other than 2 early readmissions for pleural effusions managed with diuretics, at 6 to 12 months of follow-up (mean, 8 months), all 6 patients had done well. Postoperative flow modeling demonstrated a balanced distribution of inferior vena cava flow to both pulmonary arteries with minimal flow disturbance. Improvements in hemodynamics and efficiency were noted when the Y-graft branches were anastomosed distally and aligned tangentially with the branch pulmonary arteries.

Conclusions: The present preliminary surgical experience has demonstrated the clinical feasibility of the bifurcated Y-graft Fontan. Computational fluid dynamics showed acceptable hemodynamics with low calculated power losses and a balanced distribution of inferior vena cava flow to the pulmonary arteries as long as the branch grafts were anastomosed distally. (J Thorac Cardiovasc Surg 2012;144:383-9)

The surgical management of children with single ventricle physiology using a Fontan procedure has changed considerably during the past 3 decades since the original operation described by Fontan and Baudet ${ }^{1}$ in 1977. The introduction of the concept of a total cavopulmonary connection (TCPC) described by de Leval and colleagues ${ }^{2}$ was based partially on in vitro flow modeling. Subsequent studies with computational fluid dynamics $(\mathrm{CFD})^{3}$ have demonstrated designs

From the Division of Cardiothoracic Surgery, ${ }^{\mathrm{a}}$ Department of Surgery, and Division of Pediatric Cardiology, ${ }^{\mathrm{d}}$ Department of Pediatrics, Emory University School of Medicine and Children's Healthcare of Atlanta at Egleston, Atlanta, Ga; Wallace H. Coulter Department of Biomedical Engineering, ${ }^{\text {b }}$ Georgia Institute of Technology and Emory University, Atlanta, Ga; and Georgia Institute of Technology College of Computing, ${ }^{\mathrm{c}}$ Atlanta, Ga.

This study was supported by the National Heart Lung and Blood Institute (grant HL67622) and a grant from Children's Healthcare of Atlanta (to K.R.K.)

Disclosures: Authors have nothing to disclose with regard to commercial support.

Read at the 37th Annual Meeting of The Western Thoracic Surgical Association, Colorado Springs, Colorado, June 22-25, 2011.

Received for publication June 26, 2011; revisions received April 18, 2012; accepted for publication May 9, 2012; available ahead of print June 14, 2012.

Address for reprints: Kirk R. Kanter, MD, Pediatric Cardiac Surgery, Emory University School of Medicine, 1405 Clifton Road, Northeast, Atlanta, GA 30322 (E-mail: kkanter@emory.edu).

$0022-5223 / \$ 36.00$

Copyright (c) 2012 by The American Association for Thoracic Surgery

doi:10.1016/j.jtcvs.2012.05.015 of the TCPC that can cause flow disturbances and energy dissipation. Optimizing flow and diminishing power loss in the Fontan circuit can presumably improve hemodynamic efficiency and potentially improve long-term outcomes. Previously, in vitro and CFD studies have shown reduced energy losses with caval offset ${ }^{4}$ and flaring of the cavopulmonary anastomosis, ${ }^{5}$ thus prompting modification of the TCPC surgical procedure.

In 2007, using CFD, we proposed an optimized TCPC using a bifurcated Y-graft for the superior vena cava (SVC) to the pulmonary artery connection and another bifurcated Y-graft for the inferior vena cava (IVC) to pulmonary artery connection $^{6}$ (U.S. Patent No. 7811244). Although this "Optiflo" connection had superior flow characteristics predicted by flow modeling, the optimized design appeared to be cumbersome from a surgical standpoint. Subsequent studies developing surgical designs to balance the hepatic blood flow distribution to the right and left pulmonary arteries in children with acquired pulmonary arteriovenous malformations showed favorable results with a bifurcated Y-graft connection from the IVC to the branch pulmonary arteries. ${ }^{7}$ Comparing the Y-graft Fontan connection with more conventional Fontan connections using CFD, others demonstrated improved flow characteristics, reduced 


$$
\begin{aligned}
& \text { Abbreviations and Acronyms } \\
& \text { CFD = computational fluid dynamics } \\
& \text { IVC = inferior vena cava } \\
& \text { LPA = left pulmonary artery } \\
& \text { RPA }=\text { right pulmonary artery } \\
& \text { SVC = superior vena cava } \\
& \text { TCPC = total cavopulmonary connection }
\end{aligned}
$$

energy losses, and balanced hepatic flow distribution to the pulmonary arteries. ${ }^{8,9}$ From these improvements in flow dynamics predicted by computerized modeling, we used a commercially available polytetrafluoroethylene (PTFE) bifurcated Y-graft directing IVC flow with separate graft limbs to the right pulmonary artery (RPA) and to the left pulmonary artery (LPA) in 6 consecutive children undergoing a Fontan procedure.

\section{METHODS}

The Human Investigation Committee of the Emory University School of Medicine approved the present study. The patients or parents provided informed consent.

\section{Patient Population}

From August to December 2010, 6 consecutive children undergoing a Fontan procedure aged 2.1 to 18.9 years (mean, 7.2 years; median, 4.6 years) weighing 10.3 to $50.1 \mathrm{~kg}$ (mean, $23.6 \mathrm{~kg}$; median, $18.1 \mathrm{~kg}$ ) received a completion Fontan $(n=3)$ or a Fontan revision $(n=3)$ using a commercially available bifurcated PTFE Y-graft marketed for aortoiliac reconstruction (W. L. Gore \& Associates, Flagstaff, Ariz) as an off-label use. The patient characteristics are listed in Table 1. Two patients had undergone previous Norwood palliation, 2 had pulmonary atresia with an intact ventricular septum, and 2 had a heterotaxy/unbalanced atrioventricular septal defect. Of the 3 patients undergoing a Fontan revision, both of the heterotaxy patients had developed unilateral pulmonary arteriovenous malformations. The third patient had a Fontan baffle leak that was unable to be closed with an occluder device in the catheterization laboratory. In these 3 patients undergoing Fontan revision, the interval from the original lateral tunnel fenestrated Fontan procedure was 14.0, 2.6, and 9.3 years. All 6 patients had a previous superior cavopulmonary anastomosis (a Glenn procedure) with bilateral bidirectional anastomoses in patient 6 .

To establish a 2 to 1 nonmatched comparison group with the Y-graft Fontan patients, the records of the most recent consecutive 12 patients who had undergone a more conventional Fontan procedure immediately preceding the initiation of the Y-graft series were examined to compare the preoperative, operative, and postoperative variables. The patients in the comparison group all underwent surgery by the same surgeon (K.R.K.) as the Y-graft Fontan patients. No attempt was made to match the clinical characteristics of the 6 Y-graft Fontan patients with the 12 conventional fenestrated lateral tunnel Fontan patients. The choice for the comparison group was based solely on the most recent patients undergoing a Fontan operation, with 2 "conventional" Fontan patients for each Y-graft patient. The purpose of using a nearly contemporaneous comparison group was simply to determine whether any of the common early measures of clinical progress differed significantly in the Y-graft patients. All 12 comparison patients had undergone a Fontan completion operation; none required a Fontan revision. A lateral tunnel Fontan technique with a single 2.8-mm fenestration was used in all. The "standard" Fontan comparison group underwent their operations from August 2009 to August 2010.

\section{Operative Procedure}

All operations were performed through a reoperative sternotomy using cardiopulmonary bypass with aortic and direct caval cannulation, moderate hypothermia $\left(30^{\circ} \mathrm{C}-32^{\circ} \mathrm{C}\right)$, and cold cardioplegic arrest. No attempt was made to avoid cardiopulmonary bypass using temporary venous bypass, as described by Okano and colleagues. ${ }^{10}$ After cardioplegic arrest, the right atrium was opened through a short lateral incision. For the 3 patients undergoing a Fontan revision (patients 1, 4, and 6), the previous intra-atrial lateral tunnel conduit was excised and the atriopulmonary connection repaired. Using a bifurcated PTFE Y-graft $(18 \times 9 \times 9 \mathrm{~mm}$ in 2 , $20 \times 10 \times 10 \mathrm{~mm}$ in 4 ), a single fenestration was created in the 18 - or 20 -mm portion of the graft $1 \mathrm{~cm}$ from its bifurcation. In patient 1 , because of diminished ventricular function preoperatively, a $4.0-\mathrm{mm}$ fenestration was used. For the remaining 5 patients, a single $2.8-\mathrm{mm}$ fenestration was used. To reliably ensure the patency of the fenestration, an intra/extracardiac conduit Fontan, as described by Jonas, ${ }^{11}$ was used. The graft was sewn inside the atrium around the orifice of the IVC. The 18- or 20 -mm portion of the graft was brought out through the atriotomy incision, which was closed around the graft with polypropylene suture. The 2 limbs of the bifurcated graft were anastomosed to the undersurface of the right and left branch pulmonary arteries, striving to flare the anastomosis. ${ }^{5} \mathrm{We}$ attempted to anastomose the right limb of the graft to the RPA lateral to the insertion of the SVC to the pulmonary artery, where the Glenn anastomosis had been performed to create an offset. ${ }^{4}$ The left limb of the graft was routed behind the ascending aorta and was anastomosed either to the proximal LPA or the medial portion of the proximal RPA. Postoperative management was identical to that for our "standard" Fontan patient. Only chronic low-dose daily aspirin was used routinely for thrombus prophylaxis postoperatively.

\section{Postoperative Imaging}

Postoperatively, routine transthoracic echocardiography was inadequate for providing satisfactory images of the distal anastomosis of the individual limbs of the Y-graft to the branch pulmonary arteries. As is our institutional standard of care for early postoperative Fontan patients in whom the branch pulmonary arteries cannot be adequately visualized, the Fontan baffle was imaged by magnetic resonance imaging $(\mathrm{n}=5)$ or chest computed tomography $(\mathrm{n}=1)$.Approximately 40 to 50 axial slices were collected through the thoracic region of the patient. The 3-dimensional geometries were constructed. Using CFD, phase-contrast magnetic resonance imaging-derived flows (or echocardiography/catheterization-derived flows in the patient imaged with computed tomography) were used to assess the Fontan flows from which the power losses and IVC flow splits to the branch pulmonary arteries were calculated using previously described methods. ${ }^{3,12,13}$

\section{Statistical Analysis}

Continuous variables were compared using the unpaired $t$-test and are presented as the mean \pm standard deviation. Nominal variables were compared using chi-square analysis with Fisher's exact test.

\section{RESULTS}

The operative and postoperative data are listed in Table 2. The mean aortic crossclamp and cardiopulmonary bypass time was $72 \pm 33$ and $122 \pm 56$ minutes, respectively. The mean ventilation period was $20.0 \pm 4.2$ hours, and the mean hospitalization was $9.0 \pm 3.3$ days. The systemic oxygen saturation increased from $82.0 \% \pm 7.1 \%$ preoperatively to $90.8 \% \pm 7.7 \%$ postoperatively. The only patient who did not have an immediate postoperative increase in oxygen saturations was an 18.9-year-old patient with severe pulmonary arteriovenous malformations (patient 1 ) and was 
TABLE 1. Patient characteristics

\begin{tabular}{|c|c|c|c|c|c|c|c|c|}
\hline Pt. no. & Age (y) & Wt $(\mathrm{kg})$ & $\begin{array}{l}\text { Previous } \\
\text { Norwood } \\
\end{array}$ & $\begin{array}{c}\text { Age at } \\
\text { Glenn }(y)\end{array}$ & $\begin{array}{c}\text { Interval from } \\
\text { original Fontan }(y)\end{array}$ & Primary diagnosis & Indication for Fontan & $\begin{array}{c}\text { Previous } \\
\text { operations (n) }\end{array}$ \\
\hline 1 & 18.9 & 50.1 & No & 1.38 & 14.0 & $\begin{array}{l}\text { Left atrial isomerism, common } \\
\text { AV valve, heterotaxy, } \\
\text { interrupted IVC with } \\
\text { azygos continuation }\end{array}$ & Unilateral pulmonary AVMs & 4 \\
\hline 2 & 5.4 & 17.8 & No & 0.34 & - & $\begin{array}{l}\text { Pulmonary atresia with intact } \\
\text { ventricular septum }\end{array}$ & Primary Fontan & 2 \\
\hline 3 & 2.1 & 12.3 & Yes & 0.39 & - & $\begin{array}{l}\text { Unbalanced CAVSD, hypoplastic } \\
\text { LV/aorta }\end{array}$ & Primary Fontan & 2 \\
\hline 4 & 3.7 & 18.4 & No & 0.49 & 2.6 & $\begin{array}{l}\text { Pulmonary atresia with intact } \\
\text { ventricular septum }\end{array}$ & Fontan baffle leak & 3 \\
\hline 5 & 2.3 & 10.3 & Yes & 0.35 & 一 & HLHS (AA/MA) & Primary Fontan & 2 \\
\hline 6 & 11.0 & 32.5 & No & 0.61 & 9.3 & $\begin{array}{l}\text { Right atrial isomerism, } \\
\text { hypoplastic RV, heterotaxy, } \\
\text { bilateral SVCs }\end{array}$ & Unilateral pulmonary AVMs & 3 \\
\hline
\end{tabular}

Pt. no., Patient number; $W t$, weight; $A V$, atrioventricular; $I V C$, inferior vena cava; $A V M s$, arteriovenous malformations; $C A V S D$, complete atrioventricular septal defect; $L V$, left ventricle; $H L H S$, hypoplastic left heart syndrome; $A A / M A$, aortic atresia/mitral atresia; $R V$, right ventricle; $S V C$, superior vena cava.

the only patient to have a $4.0-\mathrm{mm}$ fenestration rather than a $2.8-\mathrm{mm}$ fenestration. She had greater saturations of $85 \%$ at the 8 -month postoperative examination. Other than 2 early readmissions for pleural effusions managed with increased diuretic therapy, at 6 to 12 months of follow-up (mean, 8 months), all 6 patients were doing well clinically.

The results of a comparison of the 6 Y-graft Fontan patients with the 12 immediately preceding conventional Fontan patients are listed in Table 3. The Y-graft Fontan patients were significantly older and heavier than the lateral tunnel Fontan patients. This was because $3(50 \%)$ of the Y-graft patients had undergone revision of a previous Fontan procedure, and all 12 of the comparison group patients had undergone primary Fontan completion. The Y-graft Fontan patients had longer mean aortic crossclamp times (72 vs 49 minutes) and longer mean cardiopulmonary bypass times (122 vs 87 minutes) than the lateral Fontan patients; however, these differences did not achieve statistical significance (Table 3 ). These longer times resulted from the more extensive dissection and additional anastomosis required for the Y-graft Fontan procedure. Despite the more complex operation, the postoperative duration of inotropic support, ventilation time, intensive care unit stay, and hospital stay for the Y-graft patients were comparable to the values obtained for the lateral tunnel Fontan comparison group (Table 3 ). The preoperative and early postoperative central venous pressure measurements and duration of chest tube drainage and selected laboratory values were not significantly different statistically between the Y-graft patients and the conventional Fontan patients (Table 3).

Postoperative flow modeling generally demonstrated a balanced distribution of IVC flow to both pulmonary arteries, with minimal flow disturbances (Figure 1 and Table 4). Slight improvements in hemodynamics and efficiency were noted when the Y-graft branches were anastomosed distally and aligned tangentially with the branch pulmonary arteries (Table 4). In patient 2, failure to sufficiently offset the anastomosis of the right limb of the graft to the right pulmonary artery (Figure 1) resulted in an

TABLE 2. Operative results

\begin{tabular}{|c|c|c|c|c|c|c|c|c|c|c|}
\hline Pt. no. & $\begin{array}{c}\text { Conduit size } \\
(\mathbf{m m})\end{array}$ & $\begin{array}{c}\text { AXC time } \\
(\mathrm{min})\end{array}$ & $\begin{array}{c}\text { CPB time } \\
(\mathrm{min})\end{array}$ & Other procedures & $\begin{array}{c}\text { Inotropic } \\
\text { support } \\
\text { duration (d) } \\
\end{array}$ & $\begin{array}{c}\text { Ventilation } \\
\text { (h) }\end{array}$ & $\begin{array}{c}\text { ICU stay } \\
\text { (d) }\end{array}$ & $\begin{array}{c}\text { Hospital } \\
\text { stay (d) }\end{array}$ & $\begin{array}{c}\text { Preoperative } \\
\text { oxygen } \\
\text { saturation }(\%) \\
\end{array}$ & $\begin{array}{c}\text { Discharge } \\
\text { oxygen } \\
\text { saturation }(\%) \\
\end{array}$ \\
\hline 1 & $18 \times 9 \times 9$ & 128 & 215 & CAVV repair & 2 & 22.3 & 5 & 14 & 81 & 76 \\
\hline 2 & $20 \times 10 \times 10$ & 50 & 80 & Atrial septectomy & 1 & 18.0 & 1 & 7 & 73 & 96 \\
\hline 3 & $18 \times 9 \times 9$ & 52 & 88 & None & 1 & 17.0 & 1 & 9 & 91 & 96 \\
\hline 4 & $20 \times 10 \times 10$ & 56 & 100 & $\begin{array}{l}\text { Removal of ASD } \\
\text { device }\end{array}$ & 1 & 14.5 & 1 & 6 & 78 & 92 \\
\hline 5 & $20 \times 10 \times 10$ & 49 & 80 & None & 1 & 22.4 & 2 & 6 & 90 & 95 \\
\hline 6 & $20 \times 10 \times 10$ & 97 & 168 & None & 1 & 25.8 & 3 & 12 & 79 & 90 \\
\hline Average & & 72.0 & 121.8 & - & - & 20.0 & 2.2 & 9.0 & 82.0 & 90.8 \\
\hline
\end{tabular}

Pt. no., Patient number; $A X C$, aortic crossclamp; $A S D$, atrial septal defect occluder; $C P B$, cardiopulmonary bypass; $I C U$, intensive care unit; $C A V V$, common atrioventricular valve. 
TABLE 3. Comparison of Y-graft Fontan patients and lateral tunnel Fontan patients

\begin{tabular}{|c|c|c|c|}
\hline Variable & $\begin{array}{l}\text { Y-graft Fontan } \\
\quad(n=6)\end{array}$ & $\begin{array}{c}\text { Lateral tunnel } \\
\text { Fontan }(n=12)\end{array}$ & $\begin{array}{c}P \\
\text { value }\end{array}$ \\
\hline Age at Fontan $(y)$ & $7.2 \pm 6.6$ & $2.5 \pm 0.6$ & .022 \\
\hline Weight at Fontan $(\mathrm{kg})$ & $23.6 \pm 15.1$ & $12.1 \pm 1.6$ & $.016^{*}$ \\
\hline Previous Norwood (n) & $2(33 \%)$ & $4(33 \%)$ & $>.99$ \\
\hline $\begin{array}{l}\text { Aortic crossclamp } \\
\text { time (min) }\end{array}$ & $72.0 \pm 33.0$ & $48.8 \pm 14.6$ & .051 \\
\hline $\begin{array}{l}\text { Cardiopulmonary } \\
\text { bypass time (min) }\end{array}$ & $121.9 \pm 56.5$ & $87.2 \pm 25.7$ & .087 \\
\hline $\begin{array}{l}\text { Preoperative CVP in } \\
\text { OR }(\mathrm{mm} \mathrm{Hg})\end{array}$ & $10.0 \pm 2.2$ & $9.3 \pm 2.8$ & .622 \\
\hline $\begin{array}{l}\text { Postoperative CVP in } \\
\text { OR }(\mathrm{mm} \mathrm{Hg})\end{array}$ & $14.0 \pm 2.0$ & $14.6 \pm 2.3$ & .607 \\
\hline $\begin{array}{l}\text { CVP postoperative } \\
\text { day } 1(\mathrm{~mm} \mathrm{Hg})\end{array}$ & $14.2 \pm 1.9$ & $14.7 \pm 3.4$ & .748 \\
\hline $\begin{array}{l}\text { Postoperative inotropic } \\
\text { support duration (d) }\end{array}$ & $1.7 \pm 0.4$ & $2.0 \pm 1.5$ & .199 \\
\hline $\begin{array}{l}\text { Postoperative } \\
\text { ventilation (h) }\end{array}$ & $20.0 \pm 4.2$ & $26.7 \pm 13.3$ & .253 \\
\hline $\begin{array}{l}\text { Intensive care unit } \\
\text { stay (d) }\end{array}$ & $2.2 \pm 1.6$ & $2.4 \pm 0.8$ & .659 \\
\hline $\begin{array}{l}\text { Duration of chest tube } \\
\text { drainage (d) }\end{array}$ & $6.2 \pm 2.8$ & $6.5 \pm 1.7$ & .754 \\
\hline Hospital stay (d) & $9.0 \pm 3.3$ & $7.1 \pm 1.7$ & .124 \\
\hline $\begin{array}{l}\text { Highest postoperative } \\
\text { lactic acid (mg/dL) }\end{array}$ & $41.3 \pm 21.1$ & $30.0 \pm 13.1$ & .116 \\
\hline $\begin{array}{l}\text { Highest postoperative } \\
\text { creatinine }(\mathrm{mg} / \mathrm{dL})\end{array}$ & $0.7 \pm 0.10$ & $0.6 \pm .04$ & .372 \\
\hline $\begin{array}{l}\text { Highest postoperative } \\
\text { AST (U/L) }\end{array}$ & $88.8 \pm 21.0$ & $89.3 \pm 35.2$ & .975 \\
\hline $\begin{array}{l}\text { Highest postoperative } \\
\text { ALT (U/L) }\end{array}$ & $24.2 \pm 5.8$ & $22.4 \pm 6.9$ & .600 \\
\hline
\end{tabular}

$C V P$, Central venous pressure; $O R$, operating room; $A S T$, aspartate aminotransferase $A L T$, alanine aminotransferase. *Statistically significant.

increased calculated power loss of $2.47 \mathrm{~mW}$ and $70 \%$ of the IVC flow going to the LPA (Table 4). Similarly, in patient 5, in whom the LPA limb of the graft was brought too medially with minimal offset from the Glenn anastomosis (Figure 1), only $34 \%$ of the IVC flow was calculated to flow to the LPA (Table 4). The calculated resistances across the TCPC (Table 4) averaged 0.34 Wood units, and the average calculated power loss was $1.23 \mathrm{~mW}$.

\section{DISCUSSION}

The clinical use of a Y-graft Fontan procedure has previously been reported infrequently and always for anatomic reasons, rather than for predicted hemodynamic efficiency. Goksel and colleagues, ${ }^{14}$ from Istanbul, Turkey, used a $20 \times 10 \times 10$-mm PTFE graft in a 6-year-old patient with an unbalanced complete atrioventricular septal defect who had separate entry of the IVC and hepatic veins into the inferior portion of the right atrium. The $10-\mathrm{mm}$ limbs of the bifurcated graft were sewn inferiorly, 1 to the IVC and 1 to the hepatic veins. Only 1 connection to the pulmonary artery was made with the 20 -mm portion of the Y-graft as an extracardiac Fontan procedure. A variation of this technique using 2 inferior limbs for separate IVC and hepatic veins connecting to a single conduit to the pulmonary arteries was also mentioned in a report from Children's Hospital (Boston, Mass) on heterotaxy syndrome. ${ }^{15}$

Okano and colleagues, ${ }^{10}$ from Kyoto, Japan, described the use of a $22 \times 11 \times 11-\mathrm{mm}$ Dacron Y-graft in a 17-year-old patient with previous bilateral bidirectional Glenn anastomoses, who developed severely distorted hypoplastic central pulmonary arteries between the 2 superior cavopulmonary anastomoses. In that patient, the two 11-mm limbs of the Y-graft were anastomosed separately to the RPA and LPA, with the LPA limb brought in a nonanatomic position, anterior to the ascending aorta. Unlike the procedures in the present series, the operations described by Goksel and colleagues ${ }^{14}$ and Okano and colleagues ${ }^{10}$ were performed without the aid of cardiopulmonary bypass and without the creation of a fenestration.

Previous studies from our group predicted significant energy dissipation from head-on collision of the blood flow from the IVC with the blood flow from the SVC when the IVC portion of the TCPC is anastomosed in a T-fashion to the pulmonary artery directly opposite the connection of the SVC. ${ }^{4}$ The predicted power loss was reduced $50 \%$ with a caval offset compared with no offset. ${ }^{4}$ Flaring of the anastomosis combined with caval offset resulted in a $68 \%$ reduction in power loss, comparing the designs with no flaring or offset. ${ }^{5}$ With these concepts in mind, Soerensen and colleagues 6 proposed an idealized "Optiflo" configuration using a bifurcated Y-graft for the SVC to pulmonary artery connections and another bifurcated Y-graft for the IVC to pulmonary artery connections (U.S. Patent No. 7811244). Compared with a 1-diameter caval offset design, the Optiflo TCPC design was shown by CFD to reduce the power loss from $26 \%$ to $42 \%$ at a wide range of flows owing to the avoidance of inflow collisions. It also provided balanced hepatic blood flow distribution to the branch pulmonary arteries. In an accompanying invited commentary to that report, Hazekamp ${ }^{16}$ correctly questioned the clinical feasibility of this design in a small child.

Using computer-aided design and CFD, Marsden and colleagues ${ }^{8}$ demonstrated that the Y-graft Fontan results in greater energy efficiencies and more equal distribution of IVC flow to both lungs compared with more traditional TCPC techniques. In the same CFD study, they compared a commercially available $18 \times 9 \times 9$-mm bifurcated graft with a simulated $18 \times 12 \times 12$-mm graft and found the latter to be superior. As shown with the Optiflo model, ${ }^{6}$ under exercise conditions the efficiencies of the Y-graft design are even more pronounced compared with more standard extracardiac TCPC geometries. ${ }^{8,9}$ 


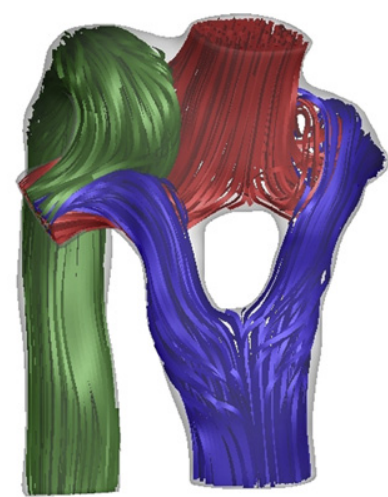

\#1: Interrupted IVC with azygos continuation

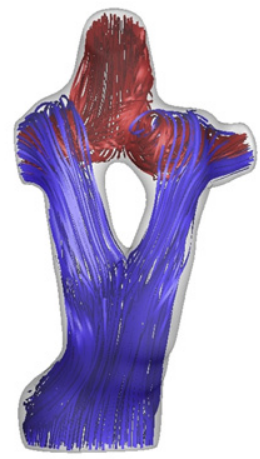

\#4

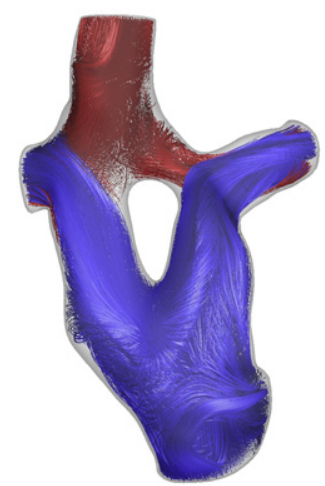

\#2: RPA limb too medial

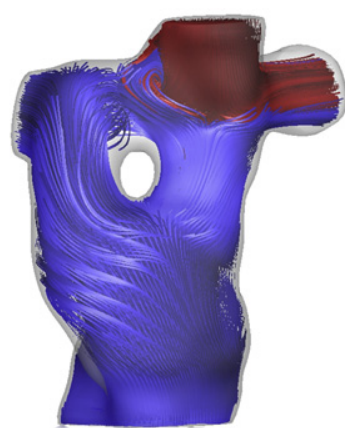

\#5: LPA limb too medial

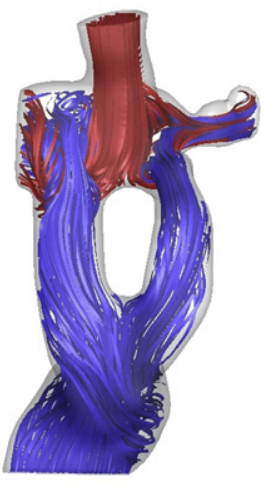

\#3

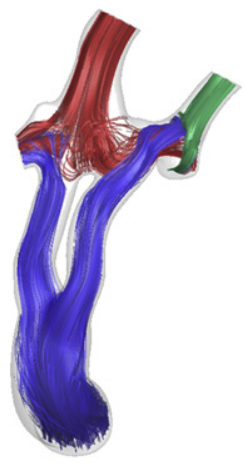

\#6: Bilateral SVCs

FIGURE 1. Computational fluid dynamics-derived 3-dimensional flow streaming in frontal orientation for all 6 patients reconstructed using magnetic resonance imaging $(n=5)$ or computed tomography $(n=1)$. In general, minimal flow disturbances and a balanced distribution of hepatic flow to the branch pulmonary arteries are present. Patients 2 and 5 had inadequate offset of 1 of the graft limbs, resulting in a decreased hepatic flow distribution to the ipsilateral lung. Patient 3 demonstrated the deleterious effect of an uncorrected left pulmonary artery (LPA) stenosis that resulted in diminished flow to the left lung and increased power loss and calculated resistance (Table 4). IVC, Inferior vena cava; $R P A$, right pulmonary artery; $S V C$, superior vena cava.

In patients with acquired pulmonary arteriovenous malformations, we used computer-based surgical modeling to predict the distribution of hepatic blood flow to the RPA and LPA. ${ }^{7,17}$ In some patients, the Y-graft Fontan was predicted to provide the most reliable solution for equalizing the hepatic blood flow distribution to both lungs. Thus, based on the predicted improved energetics

TABLE 4. Postoperative calculations

\begin{tabular}{|c|c|c|c|c|c|c|}
\hline \multirow[b]{2}{*}{ Pt. no. } & \multicolumn{3}{|c|}{ Flow (L/min) } & \multirow{2}{*}{$\begin{array}{c}\text { Power } \\
\operatorname{loss}(\mathbf{m W})\end{array}$} & \multirow{2}{*}{$\begin{array}{l}\text { IVC flow split } \\
\text { (\% to LPA) }\end{array}$} & \multirow{2}{*}{$\begin{array}{l}\text { Resistance } \\
\text { (Wood units) }\end{array}$} \\
\hline & IVC & LPA & RPA & & & \\
\hline 1 & 0.50 & 0.43 & 1.95 & 0.79 & $35 \% *$ & 0.21 \\
\hline 2 & 0.74 & 1.10 & 1.20 & 2.47 & $70 \% \dagger$ & 0.33 \\
\hline 3 & 0.29 & 0.16 & 0.32 & 2.46 & $28 \%$ & 0.88 \\
\hline 4 & 0.65 & 0.32 & 0.63 & 0.42 & $45 \%$ & 0.14 \\
\hline 5 & 0.37 & 0.64 & 0.23 & 0.25 & $34 \% \dagger$ & 0.16 \\
\hline 6 & 0.44 & 0.84 & 0.39 & 0.99 & $30 \% \ddagger$ & 0.33 \\
\hline
\end{tabular}

Pt. no., Patient number; $I V C$, inferior vena cava; $L P A$, left pulmonary artery; $R P A$, right pulmonary artery; $M R I$, magnetic resonance imaging; $S V C$, superior vena cava. *Interrupted IVC with azygos continuation. †Postoperative MRI showed RPA or LPA limb of graft directly opposite Glenn anastomosis. ‡Bilateral SVCs. using CFD models with the described Optiflo and Y-graft designs (especially under simulated exercise conditions) and reliably balanced hepatic blood flow distribution to both lungs, we decided to apply the Y-graft Fontan connection clinically, which was the basis for the present report.

Clinically, all 6 patients in the present series did well with successful operations and a reasonable postoperative length of ventilation, intensive care unit stays, and hospital stays (Table 2). Compared with an almost contemporaneous nonmatched group of 12 patients who underwent a more standard fenestrated lateral tunnel Fontan procedure, despite longer crossclamp and bypass times, the postoperative duration of inotropic support, mechanical ventilation, intensive care unit stay, duration of chest tube drainage, selected laboratory results, and hospital length of stay were quite similar (Table 3 ). The early imaging results demonstrated the potential pitfalls to this operation. In 2 patients (patients 2 and 5), minimal offset of 1 of the limbs of the bifurcated graft occurred, resulting in moderate maldistribution of the hepatic flow to the lungs (Figure 1 and Table 4). We have 
previously reported that caval offset significantly influences the hepatic blood flow distribution in the extracardiac and lateral tunnel TCPCs. ${ }^{12}$ In patient 2 , there was also an increased calculated power loss that did not occur in patient 5 , possibly explained by the use of a relatively large $20 \times 10 \times 10$-mm graft in a small $10.3-\mathrm{kg}$ child. Despite these issues with inadequate offset, in all 6 patients, the less-perfused lung always received more than one quarter of the IVC flow (Table 2).

In all but patient 3 , the calculated resistances across the TCPC (Table 4) were lower than the average TCPC resistance of $0.39 \pm 0.26$ Wood units previously reported by our group for more standard extracardiac and lateral tunnel Fontan geometries. ${ }^{13}$ The average calculated power losses of $1.23 \mathrm{~mW}$ (Table 4) were also lower than the published values predicted for more standard TCPCs. ${ }^{3}$ Patient 3 had a greater calculated power loss and TCPC resistance than the other Y-graft patients (Table 4). Most likely, these mildly unfavorable energetics were more related to an uncorrected stenosis of the LPA (Figure 1) than a problem with the Y-graft Fontan connection. We have previously shown that distortion of the branch pulmonary arteries negatively affects energy loss far more strongly than the type of TCPC used. ${ }^{18}$ Probably for the same anatomic reason, patient 3 had only $28 \%$ of the IVC flow directed to the LPA (Table 4).

Because the present study reports a preliminary clinical application of the Y-graft Fontan procedure, several questions remain unanswered. We chose to perform all the operations with cardiopulmonary bypass and cardioplegic arrest. Undoubtedly, this procedure can be performed safely without cardiopulmonary bypass, with or without venous shunting, as suggested previously. ${ }^{10,14}$ Also, because of the ease and reliability of creating a fenestration, we chose to use elements of the intra/extracardiac Fontan procedure, ${ }^{11}$ rather than constructing a completely extracardiac Fontan connection. Certainly, the Y-graft Fontan can be performed completely as an extracardiac connection.

Finally, for convenience, although it represented off-label use, we chose the commercially available $18 \times 9 \times 9$-mm or $20 \times 10 \times 10$-mm PTFE bifurcated Y-grafts rather than constructing what theoretically would appear to be a more energetically favorable $18 \times 12 \times 12$-mm Y-graft, as suggested by Marsden and colleagues. ${ }^{8}$ In their report, the calculated efficiency at rest of the $18 \times 8 \times 9$-mm graft was $88.5 \%$ compared with $90.3 \%$ for an $18 \times 12 \times 12-\mathrm{mm}$ graft. However, the difference in energy efficiency was much more pronounced under simulated exercise conditions. The calculated combined cross-sectional area of the 2 limbs of a bifurcated graft are one half that of the main graft if the diameter of each limb is one half that of the main graft $\left(A=\pi r^{2}\right)$. For example, for the $18 \times 9 \times 9$-mm graft, the combined cross-sectional area of the two $9-\mathrm{mm}$ limbs is $127.2 \mathrm{~mm}^{2}$ compared with a cross-sectional area of $254.4 \mathrm{~mm}^{2}$ for the $18-\mathrm{mm}$ portion. Similarly, for the $20 \times 10 \times 10$-mm graft, the combined cross-sectional area of the two $10-\mathrm{mm}$ limbs is $157 \mathrm{~mm}^{2}$ compared with a cross-sectional area of $314 \mathrm{~mm}^{2}$ for the $20-\mathrm{mm}$ portion. To achieve the same cross-sectional area as the main graft, the diameter of each limb would have to be one half the diameter of the main graft multiplied by $\sqrt{2}$. Thus, to maintain equal combined cross-sectional areas, the branches for an $18-\mathrm{mm}$ graft should each have a diameter of $12.7 \mathrm{~mm}(18 \times 12.7 \times 12.7 \mathrm{~mm})$. For the $20-\mathrm{mm}$ graft, each limb would need a diameter of $14.1 \mathrm{~mm}(20 \times 14.1 \times 14.1 \mathrm{~mm})$. To construct such a bifurcated graft that preserves the total cross-sectional area of the main portion into the separate limbs would require either collaboration with industry or the fashioning of individual "home-made" grafts. Only time and additional study will demonstrate whether this theoretical geometric advantage is clinically important.

\section{CONCLUSIONS}

We have shown the clinical feasibility of a Y-graft Fontan connection with excellent clinical results during very short follow-up. Early imaging and CFD studies demonstrated acceptable hemodynamics and hepatic blood flow distribution. The degree of offset and flaring of the upper limbs of the Y-graft to the pulmonary arteries appear to be important factors for optimizing favorable hemodynamics. The critical unanswered question from the present study is whether the computationally predicted improved energetics (especially during exercise), flow characteristics, and balanced hepatic flow distribution will translate into improved long-term clinical outcomes.

\section{References}

1. Fontan F, Baudet E. Surgical repair of tricuspid atresia. Thorax. 1971;26:240-8.

2. de Leval MR, Kilner P, Gewillig M, Bull C. Total cavopulmonary connection: a logical alternative to atriopulmonary connection for complex Fontan operations. Experimental studies and early clinical experience. J Thorac Cardiovasc Surg. 1988;96:682-95

3. Whitehead KK, Pekkan K, Kitajima HD, Paridon SM, Yoganathan AP, Fogel MA. Nonlinear power loss during exercise in single-ventricle patients after the Fontan: insights from computational fluid dynamics. Circulation. 2007;116:I165-71.

4. Sharma S, Goudy S, Walker P, Panchal S, Ensley A, Kanter K, et al. In vitro flow experiments for determination of optimal geometry of total cavopulmonary connection for surgical repair of children with functional single ventricle. J Am Coll Cardiol. 1996;27:1264-9.

5. Ensley AE, Lynch P, Chatzimavroudis GP, Lucas C, Sharma S, Yoganathan AP. Toward designing the optimal total cavopulmonary connection: an in vitro study. Ann Thorac Surg. 1999;68:1384-90.

6. Soerensen DD, Pekkan K, de Zelicourt D, Sharma S, Kanter K, Fogel M, et al. Introduction of a new optimized total cavopulmonary connection. Ann Thorac Surg. 2007;83:2182-90.

7. de Zelicourt DA, Haggerty CM, Sundareswaran KS, Whited BS, Rossignac JR, Kanter KR, et al. Individualized computer-based surgical planning to address pulmonary arteriovenous malformations in patients with a single ventricle with an interrupted inferior vena cava and azygos continuation. $J$ Thorac Cardiovasc Surg. 2011;141:1170-7.

8. Marsden AL, Bernstein AJ, Reddy VM, Shadden SC, Spilker RL, Chan FP, et al. Evaluation of a novel Y-shaped extracardiac Fontan baffle using computational fluid dynamics. J Thorac Cardiovasc Surg. 2009;137:394-403. 
9. Yang W, Feinstein JA, Marsden AL. Constrained optimization of an idealized Y-shaped baffle for the Fontan surgery at rest and exercise. Comp Meth Appl Mech Eng. 2010;199:2135-49.

10. Okano T, Yamagishi M, Shuntoh K, Yamada Y, Hayashida K, Shinkawa T, et al. Extracardiac total cavopulmonary connection using a Y-shaped graft. Ann Thorac Surg. 2002;74:2195-7.

11. Jonas RA. The intra/extracardiac conduit fenestrated Fontan. Semin Thorac Cardiovasc Surg Pediatr Card Surg Ann. 2011;14:11-8.

12. Dasi LP, Whitehead K, Pekkan K, de ZD, Sundareswaran K, Kanter K, et al. Pulmonary hepatic flow distribution in total cavopulmonary connections: extracardiac versus intracardiac. J Thorac Cardiovasc Surg. 2011;141:207-14.

13. Sundareswaran KS, Pekkan K, Dasi LP, Whitehead K, Sharma S, Kanter KR, et al. The total cavopulmonary connection resistance: a significant impact on single ventricle hemodynamics at rest and exercise. Am J Physiol Heart Circ Physiol. 2008;295:H2427-35.
14. Goksel OS, Tireli E, Sungur Z, Harmandar B, Nisli K, Dayioglu E. Use of a bifurcated ePTFE graft for off-pump extracardiac Fontan completion. Thorac Car diovasc Surg. 2007;55:324-5.

15. Stamm C, Friehs I, Duebener LF, Zurakowski D, Mayer JE Jr, Jonas RA, et al. Improving results of the modified Fontan operation in patients with heterotaxy syndrome. Ann Thorac Surg. 2002;74:1967-77.

16. Hazekamp M. Invited commentary: introduction of a new optimized total cavopulmonary connection. Ann Thorac Surg. 2007;83:2190.

17. Sundareswaran KS, de Zelicourt D, Sharma S, Kanter KR, Spray TL, Rossignac J, et al. Correction of pulmonary arteriovenous malformation using image-based surgical planning. J Am Coll Cardiol Img. 2009;2: 1024-30.

18. Dasi LP, Krishnankuttyrema R, Kitajima HD, Pekkan K, Sundareswaran KS, Fogel M, et al. Fontan hemodynamics: importance of pulmonary artery diameter J Thorac Cardiovasc Surg. 2009;137:560-4. 